\title{
Research on Evaluation and Improvement Policy of Higher Education Development Based on TOPSIS-Synthetic Control Method
}

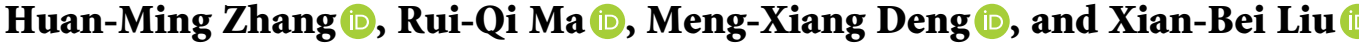 \\ School of Statistics and Applied Mathematics, Anhui University of Finance and Economics, Bengbu 233030, China \\ Correspondence should be addressed to Xian-Bei Liu; liuxianbei82@163.com
}

Received 10 May 2021; Accepted 26 May 2021; Published 3 June 2021

Academic Editor: Huihua Chen

Copyright (c) 2021 Huan-Ming Zhang et al. This is an open access article distributed under the Creative Commons Attribution License, which permits unrestricted use, distribution, and reproduction in any medium, provided the original work is properly cited.

\begin{abstract}
This article aims at the evaluation and improvement of the development of higher education. First of all, according to the theory and hypothesis, the comprehensive evaluation index system of higher education development level is established. The TOPSIS and the combination weighting method based on goal programming are used to measure the scores of higher education development levels of 19 major countries in the world in the recent 20 years, and the horizontal and vertical comparative analysis is carried out. Then, according to the practical feasibility, Turkey is selected as the target country to propose a higher education development and improvement policy by 2030, and the causal effect of our proposed policy is estimated using the synthetic control method. This study can provide a reference for other countries in the world to improve their higher education level.
\end{abstract}

\section{Introduction}

Higher education is a professional education based on completing secondary education. It is the main social system to cultivate professional and innovative talents. Since the last century, the modern economic growth theory believes that technological progress and human capital are the sources of long-term economic growth [1-3]. The university is usually the main place of innovation and is the core way to cultivate innovation and get human capital store $[4,5]$. Therefore, countries all over the world attach great importance to developing their own higher education [6].

The existing literature mainly gets the empirical facts to develop higher education, which positively impacts the real world through the following. Firstly, the "renewal of industrial" based on higher education is the driving force to realize the gradient transfer of the economy. In an innovation-oriented economy, the government, enterprises, and higher education institutions will be linked by the market [6-9]. Secondly, education can make social distribution more equal. According to Schultz's human capital theory, uneven education level is the main source of the wage gap. With extending compulsory education and improving the higher education enrollment rate, social income inequality increases [10-12]. Thirdly, from the micro level, higher education is an important way to promote individual human development. Positive psychology believes that higher education can improve people's cognitive ability and can also transform and construct the subjective world of human beings. This cannot only make individuals more likely to get happiness but also transform education into an intangible capital that can bring economic benefits [13-16].

Because of the importance of higher education development, we will set up a comprehensive evaluation index of higher education development. This article measures the development of higher education in 19 major countries in the world from 2000 to 2019 and finds out the convergence between the development of higher education in various countries and the development of the real world. This article also puts forward a long-term plan to develop higher education in a country with development potential and verifies the effectiveness of the policies we provide. This can provide 
useful policy reference for other countries in the world to improve higher education. The process of this article is displayed in Figure 1.

\section{Assumptions}

In order to solve the problem of this article, we need to make the following assumptions: (i) it is assumed that all the data used are authentic; (ii) it is assumed that the index values of each country are predictable, and the future trend of the index values is consistent with the predicted results; (iii) it is assumed that there will be no war, serious natural disasters, and other exogenous factors interfering with higher education development in the sample countries in the next 10 years; (iv) it is assumed that the policy plan for the target country can be gradually completed according to the schedule.

\section{Comprehensive Evaluation of Higher Education Development}

3.1. Construction of the Evaluation Index System. To measure the development level of higher education, it is necessary to establish a reasonable comprehensive evaluation index system. The establishment of the comprehensive evaluation index system of higher education development level needs to meet the following four requirements [17]:

(i) Decision orientation: index design should depend on the needs of the subject and evaluation purpose

(ii) Comparability: the index system can be compared horizontally and vertically in the world

(iii) Relativity: because there are great differences in the development of countries in the world, relative indicators should be used instead of absolute indicators

(iv) Operability: in order to ensure the operability and practicability of the evaluation, the availability of data should be considered in the design of indicators

By combining the theoretical research, higher education construction is essentially an investment activity and investment means input and output, so it is necessary to add indicators that can measure the input and output level of higher education in the index system. For example, the input indicators should include government expenditure, and the output indicators should include the scientific rewards and social benefits brought by higher education [18-20]. Moreover, the construction of a country's higher education cannot do without strong economic strength and effective market innovation demand as support, so we need to add these potential factors into the index system [21]. Finally, the index system also needs to describe the scale and structural characteristics of the higher education system, such as the coverage of higher education, faculty strength, and internationalization [22-24]. According to the above index selection principles, the comprehensive evaluation index system of higher education development is formed, as shown

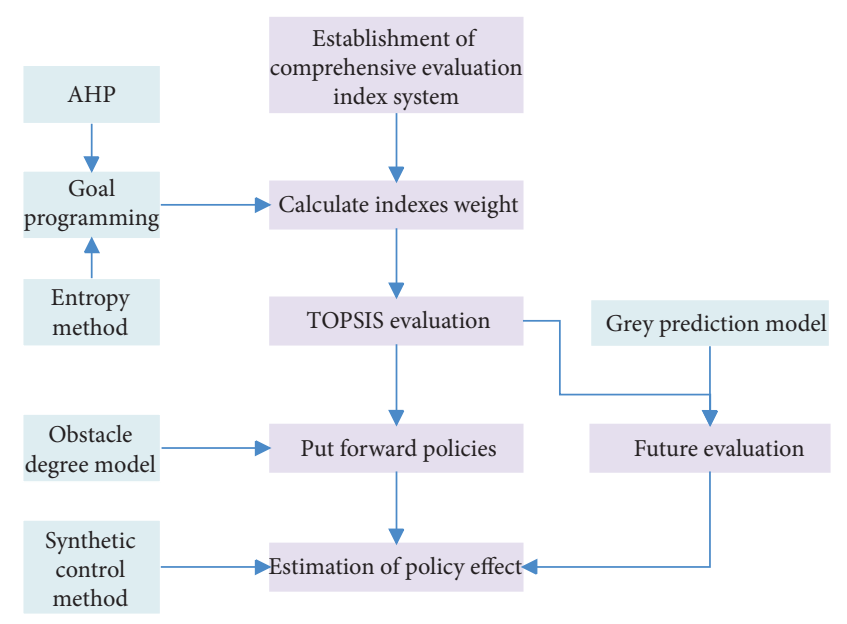

FIgURE 1: Overall thinking process.

in Figure 2. The data of all indicators are from the World Bank database.

3.2. Data Standardization. Before the comprehensive evaluation, it is necessary to standardize the sample values of each index to remove different dimensions and make the direction of all indexes consistent. Suppose the dataset is $X=\left\{x_{i j}\right\}, i=\{1,2, \ldots, n\}$ is the scheme, and $j=\{1,2$, $\ldots, m\}$ is the index. For the positive index, the data standardization can be transformed as follows:

$$
z_{i j}=\frac{x_{i j}-M_{j}}{M_{j}-m_{j}}
$$

$M_{j}=\max _{1 \leq i \leq n} x_{i j}, m_{j}=\min _{1 \leq i \leq n} x_{i j}$; the data transformation of the negative index is as follows:

$$
z_{i j}=\frac{M_{j}-x_{i j}}{M_{j}-m_{j}} .
$$

The data transformation of the intermediate index is as follows:

$$
z_{i j}= \begin{cases}1-\frac{q-x_{i j}}{\max \left\{q-m_{j}, M_{j}-q_{2}\right\}}, & \text { if } x_{i j}<q, \\ 1, & \text { if } x_{i j}=q, \\ 1-\frac{x_{i j}-q}{\max \left\{q-m_{j}, M_{j}-q_{2}\right\}}, & \text { if } x_{i j}>q .\end{cases}
$$

In the comprehensive evaluation index system of higher education development, A2 and D4 are negative indicators, D2 is the intermediate indicator, and the rest are positive indicators. According to the above method, we can get the standardized dataset: $Z=\left\{z_{i j}\right\}$.

3.3. Calculation Method of Comprehensive Score. Because the importance of each index in the index system is different, we use the weighting method to calculate the weight of each 


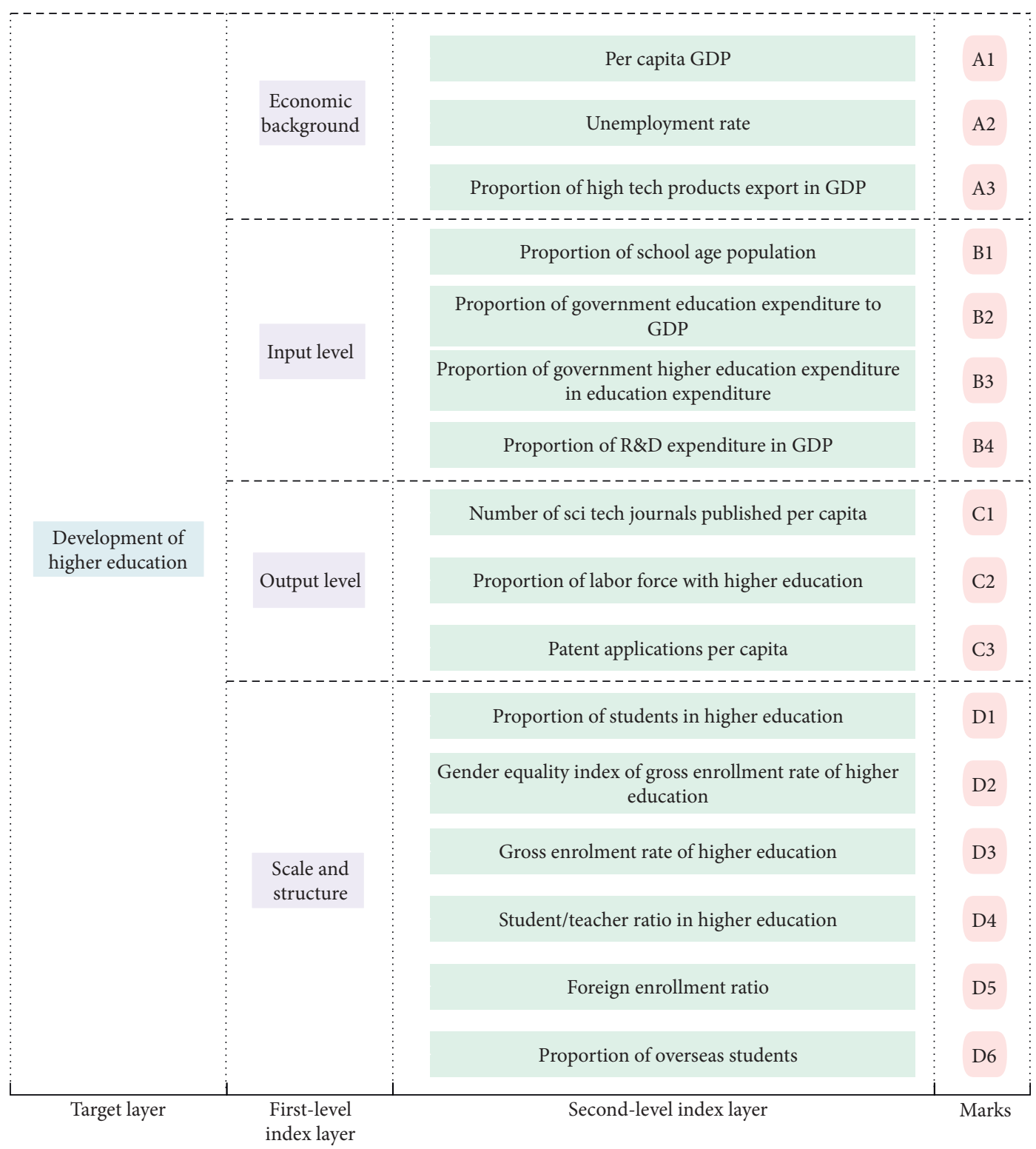

FIGURE 2: Comprehensive evaluation index system of development level of higher education.

index. The weighting method mainly includes subjective weighting method, objective weighting method, and integrated weighting method. The subjective weighting method measures the index weight according to the experience and judgment of decision-makers, while the objective weighting method measures the index weight according to the objective information provided by the data itself. Both subjective and objective weighting methods have limits and onesidedness, while the integrated weighting method can effectively combine subjective and objective weighting methods. Therefore, in this article, we use the integrated weighting method based on goal programming to combine the subjective weight with the objective weight [25].
AHP is the most common subjective weighting method. Firstly, the discriminant matrix $A$ is established according to the membership relationship of the index system:

$$
A=\left(\begin{array}{cccc}
a_{11} & a_{12} & \cdots & a_{1 n} \\
a_{21} & a_{22} & \cdots & a_{2 n} \\
\vdots & \vdots & \ddots & \vdots \\
a_{n 1} & a_{n 2} & \cdots & a_{n n}
\end{array}\right),
$$

where $n$ is the number of evaluation indicators. The corresponding element $a_{i j}$ in the discrimination matrix $A$ means the importance of index $i$ compared with index $j$, in 
which the importance is measured by the 1-9 scale method. So $A$ is a positive reciprocal matrix, and the main diagonal elements are all one. Then, the weight vectors of each index are obtained using arithmetic average method $v_{j}$ :

$$
v_{j}=\frac{1}{n} \sum_{j=1}^{n} \frac{a_{i j}}{\sum_{k=1}^{n} a_{k j}} .
$$

The rationality of the judgment matrix should be examined by the consistency ratio (CR) test. If the consistency ratio is less than 0.1 , the consistency of the judgment matrix can be considered acceptable. Otherwise, it is necessary to modify the judgment matrix.

$$
\begin{aligned}
\mathrm{CI} & =\frac{\left(\lambda_{\max }-n\right)}{(n-1)}, \\
\mathrm{CR} & =\frac{\mathrm{CI}}{\mathrm{RI}}
\end{aligned}
$$

In equation (6), $\lambda_{\max }$ represents the maximum eigenvalue of $A$, and RI represents the average random consistency index.

The entropy method is a typical objective weighting method. First, calculate the proportion of the $i$-th scheme in the $j$-th index:

$$
P_{i j}=\frac{z_{i j}}{\sum_{i=1}^{n} z_{i j}} \text {. }
$$

Then, we calculate the entropy $e_{j}$ of the $j$-th index:

$$
e_{j}=-\frac{1}{\ln n} \times \sum_{i=1}^{n} P_{i j} \ln \left(P_{i j}\right)>0 .
$$

Next, we calculate the weight of each index by entropy method:

$$
u_{j}=\frac{\left(1-e_{j}\right)}{\sum_{j=1}^{m}\left(1-e_{j}\right)} .
$$

For the subjective weight vector $v_{j}$ obtained by AHP and the objective weight $u_{j}$ obtained by entropy method, the combination weights can be obtained using the goal programming method. follows:

Firstly, suppose a group of combination weights are as

$$
C=\left(c_{1}, c_{2}, \ldots, c_{m}\right)^{T} \text {. }
$$

The above combination weights satisfy $\sum_{j=1}^{m} c_{j}=1, c_{j} \geq 0$. In order to make full use of the information contained in the dataset, and at the same time consider the decision-maker's personal preference, we continue to introduce the deviation function:

$$
\begin{aligned}
& d_{i}=\sum_{j=1}^{m}\left[\left(c_{j}-v_{j}\right) z_{i j}\right]^{2}, \\
& h_{i}=\sum_{j=1}^{m}\left[\left(c_{j}-u_{j}\right) z_{i j}\right]^{2} .
\end{aligned}
$$

Among them, the deviation function $d_{i}$ represents the deviation between the decision made by the subjective weighting method (AHP) and the decision made by the combination weight of the $i$-th scheme; the deviation function $h_{i}$ represents the deviation between the decision made by the objective weighting method (entropy method) and the decision made by the combination weight of the $i$-th scheme; obviously, we hope that the combination weight can minimize the total deviation; therefore, we construct a goal programming model as follows:

$$
\left\{\min \mu \sum_{i=1}^{n} d_{i}+(1-\mu) \sum_{i=1}^{n} h_{i} \text {, s.t. } \sum_{j=1}^{m} c_{j}=1, c_{j} \geq 0 .\right.
$$

$\mu$ represents the preference factor of the dispersion function. When $0<\mu<0.5$, the decision-maker thinks that objective weighting is more important. When $0.5<\mu<1$, the decisionmaker prefers subjective weighting. When $\mu=0.5$, the decision-maker thinks that subjective weighting is as important as objective weighting. Usually, the expert's or decisionmaker's experienced judgment is more important when calculating the index weight, so this article sets the preference factor $\mu$ equal to 0.6 . The combination weight can be obtained by solving the model (12).

We can continue to use the TOPSIS method combined with a combination weight vector to calculate the higher education development level score of each country at each time point. TOPSIS is a classical method to solve multiobjective decision-making problems. According to the standardized dataset $Z=\left\{z_{i j}\right\}$, a weighted normalization matrix can be established:

$$
B=Z \times C=\left\{b_{i j}\right\}_{n \times m} .
$$

Then, we determine the positive ideal solution vector $B^{+}$ and the negative ideal solution vector $B^{-}$:

$$
\begin{aligned}
& B^{+}=\max _{1 \leq i \leq n} z_{i j}, \\
& B^{-}=\min _{1 \leq i \leq n} z_{i j} .
\end{aligned}
$$

Next, we calculate the Euclidean distance between each scheme and the positive and negative ideal solutions:

$$
\begin{aligned}
& D^{+}=\sqrt{\sum_{j=1}^{m}\left(B-B^{+}\right)^{2}}, \\
& D^{+}=\sqrt{\sum_{j=1}^{m}\left(B-B^{-}\right)^{2}} .
\end{aligned}
$$

Finally, we calculate the TOPSIS score of each scheme:

$$
S=\frac{D^{-}}{\left(D^{+}+D^{-}\right)}
$$

3.4. Calculation Results. Firstly, according to the index weight calculation method provided above, we calculated the combination weights of 16 secondary indicators, as shown in Table 1. According to Table 1, the top five indexes with the 
TABLe 1: Calculation results of combination weight method.

\begin{tabular}{lcccccccc}
\hline Index & $\mathrm{A} 1$ & $\mathrm{~A} 2$ & $\mathrm{~A} 3$ & $\mathrm{~B} 1$ & $\mathrm{~B} 2$ & $\mathrm{~B} 3$ & $\mathrm{~B} 4$ & $\mathrm{C} 1$ \\
\hline Weights & 0.149 & 0.026 & 0.081 & 0.025 & 0.035 & 0.046 & 0.054 & 0.080 \\
Index & $\mathrm{C} 2$ & $\mathrm{C} 3$ & $\mathrm{D} 1$ & $\mathrm{D} 2$ & $\mathrm{D} 3$ & $\mathrm{D} 4$ & $\mathrm{D} 5$ & $\mathrm{D} 6$ \\
Weights & 0.070 & 0.128 & 0.042 & 0.064 & 0.032 & 0.062 & 0.056 & 0.051 \\
\hline
\end{tabular}

largest proportion are GDP per capita, patent application volume, export proportion of high-tech products, articles in sci-tech journals, and labor force with higher education. It can be seen that if a country wants to achieve a higher level of higher education development, it must have a strong economic background and innovation ability because economic strength is the supporting condition for higher education and innovation is the main product of higher education development. This phenomenon is also consistent with the reality of several major higher education powers or innovative countries (such as the United States and the United Kingdom).

According to the combination weight, we continue to use the TOPSIS method to calculate the higher education development scores of 19 countries. Figure 3 shows the heatmap of higher education development scores of 19 countries in the past 20 years.

Through horizontal comparison, it is found that the United States, Australia, the United Kingdom, Canada, and France are among the top five, and their average TOPSIS score is more than 0.5 , belonging to the countries or regions with very good development level of higher education. The average TOPSIS scores of South Korea, Germany, Japan, Mexico, and China rank 6-10, belonging to the countries or regions with good development of higher education. The average scores of Brazil, Saudi Arabia, Italy, Indonesia, and Argentina rank 11-15, belonging to the countries with general higher education level. Turkey, South Africa, Russia, and India are the last four countries with relatively low development of higher education. From the perspective of vertical comparison, the higher education level of some Asian countries has achieved relatively rapid development. South Korea, for example, has risen from a general level to a very good level. This phenomenon is consistent with the rapid economic growth of some Asian countries in the past 20 years.

\section{Putting Forward Improvement Policy}

4.1. Choosing a Study Subject. After measuring the health level of higher education in 19 countries, we can further put forward some targeted improvement policies for a specific country or region, formulate the corresponding policy implementation schedule, and verify the effectiveness of our proposed improvement policies so as to provide some policy reference for other countries in the world to work out appropriate higher education improvement plans.

We need to select the research object from the countries (Turkey, South Africa, Russia, and India) with relatively low level of development of higher education so as to make the policy plan more effective or more universal. Moreover, in order to meet the policy assumptions, the target countries need to have a stable international political environment and economic development space.

Turkey is located across Asia and Europe. It implements the European model in politics, economy, culture, and other fields. The focus of foreign affairs and trade is in western developed countries, and it has a strong industrial base. At present, Turkey is one of the emerging economies in the world and one of the fastest-growing countries in the world. Therefore, compared with South Africa, Russia, and India, Turkey has a more reasonable population density and structure and can maintain domestic political and economic stability in the future. We finally set Turkey as the target country of improvement policy-making in higher education.

4.2. Developing an Improvement Policy. In order to clarify the healthy development of Turkey's higher education system, the improvement direction of the coordinated development of internal subsystems, and formulate reasonable policies. This article uses the obstacle factor diagnosis model to analyze the obstacle factors of the development of higher education system in the target countries [26]. The calculation formula is as follows:

$$
O_{j}=\frac{\left(1-z_{i j}\right) \times c_{j}}{\sum\left(1-z_{i j}\right) \times c_{j}} .
$$

$O_{j}$ is the obstacle degree of the second-level index $j$ to the development of higher education. $c_{j}$ is the weight value of the $j$ second-level index in the first-level index $i$. Then, we get the average ranking of the obstacle degree of the indicators of Turkey's higher education development from 2000 to 2019, as shown in Figure 4.

In our opinion, the obstacle degree of a certain index above $6 \%$ can be regarded as the core factor hindering the development of higher education. According to Figure 3, the indicators of obstacle degree above $6 \%$ include per capita GDP, patent applications per capita, the proportion of hightech products export in GDP, number of sci-tech journals published per capita, foreign enrollment ratio, and proportion of $\mathrm{R} \& \mathrm{D}$ expenditure in GDP.

The core obstacle factors all involve four first-level indicators. According to the realistic conditions and assumptions, we formulate Turkey's long-term planning policy for the improvement of higher education in 2020-2030 as follows:

(i) Per capita GDP will increase to $\$ 20000$ by 2030

(ii) The export proportion of high-tech products increased to $2.8 \%$

(iii) Increase the proportion of R\&D expenditure to 3\%

(iv) The number of papers published in sci-tech journals will reach 100000

(v) The number of patent applications will increase to 40000

(vi) The proportion of international students should reach $1 \%$ 


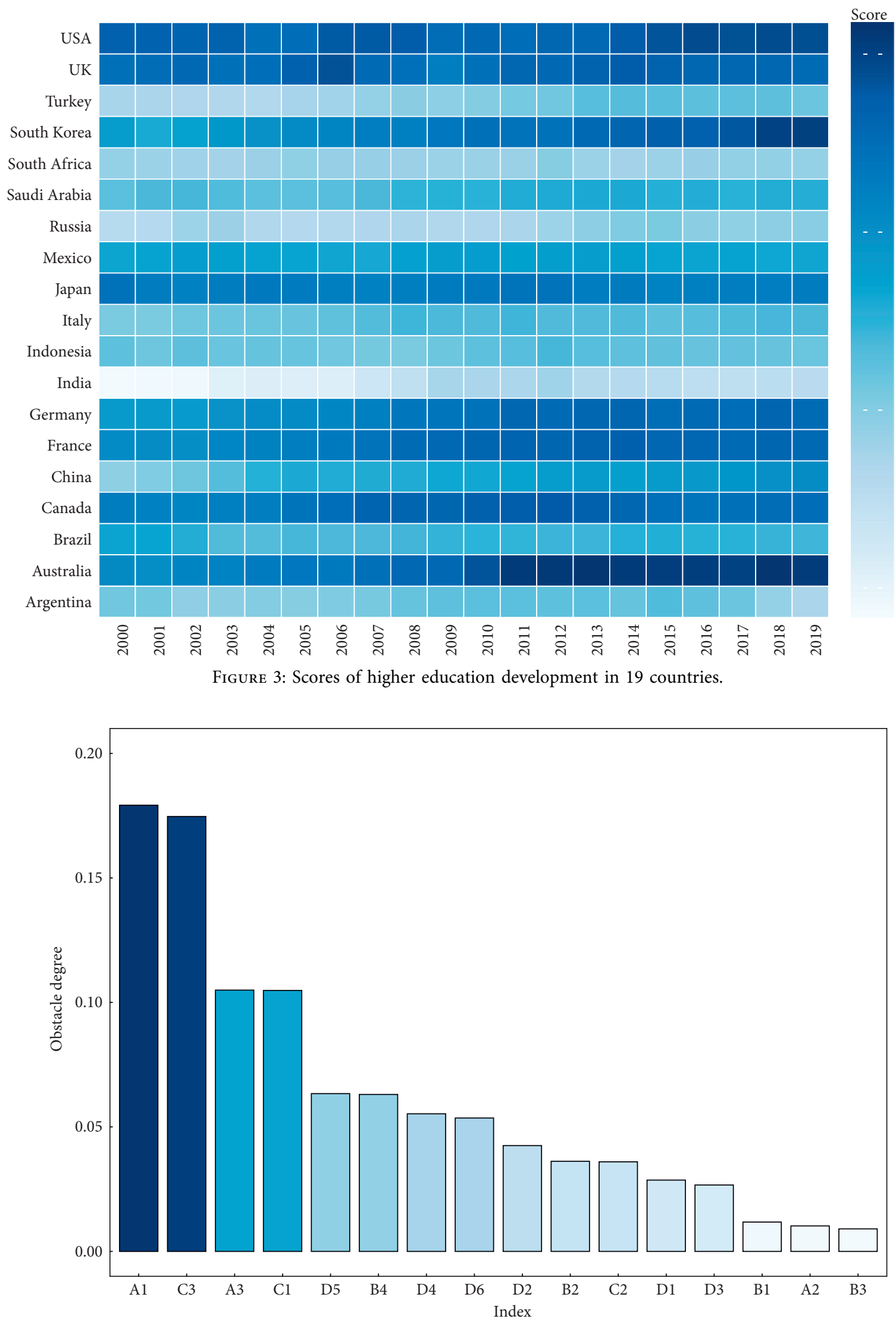

FIGURE 4: Obstacle degree of indicators for the development of higher education in Turkey. 
Theoretically speaking, the formulation of the above six long-term plans can form a virtuous circle in the internal subsystem of higher education development so that the policies can maintain long-term effectiveness. The circular promotion mechanism generated by policy implementation is shown in Figure 5.

\section{Prediction of Policy Implementation Effect}

5.1. Extended Grey Prediction Model. In order to obtain the future trend of the development of higher education in various countries, we need to establish a reasonable prediction model. At present, the mainstream prediction models are ARIMA, neural network model, etc., but these prediction methods often need a large number of samples as a prerequisite $[27,28]$. In this study, the longitudinal length of panel data is only 20 years, which is difficult to meet the data requirements of ARIMA and other models. However, the grey prediction model proposed by Deng et al. can solve the problem of short- and medium-term time series prediction reasonably [29]. Assume the original data sequence is $x^{(0)}=\left(x^{(0)}(1), x^{(0)}(2), \ldots, x^{(0)}(n)\right)$. A new data sequence $x^{(1)}$ is obtained by accumulating $x^{(0)} \cdot x^{(1)}$ represents the 1-AGO sequence of $x^{(0)}$ :

$$
x^{(1)}=\left(x^{(1)}(1), x^{(1)}(2), \ldots, x^{(1)}(n)\right) .
$$

In formula (18), $x^{(1)}(m)=\sum_{i=1}^{m} x^{(0)}(i), m=1,2, \ldots, n$. Let $z^{(1)}$ be the nearest mean generating sequence of $x^{(0)}$ :

$$
z^{(1)}=\left(z^{(1)}(1), z^{(1)}(2), \ldots, z^{(1)}(n)\right) .
$$

In formula (19), $z^{(1)}(m)=\delta x^{(1)}(m)+(1-\delta) x^{(1)}(m-1)$, $m=2,3, \ldots, n$ and $\delta=0.5$. The basic form of the GM $(1,1)$ model is obtained:

$$
x^{(0)}(k)+a z^{(1)}(k)=b, \quad k=2,3, \ldots, n,
$$

where $-a$ is the development coefficient, $b$ is the amount of grey crop, and parameters $a$ and $b$ can be estimated by least square method (OLS). According to the Newton-Leibniz formula, we can get the whitening differential equation of GM $(1,1)$ :

$$
\frac{\mathrm{d} x^{(1)}(k)}{\mathrm{d} t}=-\widehat{a} x^{(1)}(k)+\widehat{b}
$$

If we take the initial value $\left.x^{(1)}(k)\right|_{t=1}=x^{(0)}(k)$ to solve the above whitening equation, we can obtain the following results:

$$
\begin{aligned}
& \widehat{x}^{(1)}(m+1)=\left[x^{(1)}(1)-\frac{\hat{b}}{\hat{a}}\right] e^{-\widehat{a} m}+\frac{\widehat{b}}{\hat{a}}, \quad m=1,2, \ldots, n-1, \\
& \widehat{x}^{(0)}(m+1)=\hat{x}^{(1)}(m+1)-\hat{x}^{(1)}(m)=\left(1-e^{\widehat{a}}\right)\left[x^{(0)}(1)-\frac{\hat{b}}{\hat{a}}\right] e^{-\widehat{a} m} .
\end{aligned}
$$

The GM $(1,1)$ model based on the original sequence $x^{(0)}$ is called full data GM $(1,1)$. Let $x^{(0)}(n+1)$ be the latest prediction information and put $x^{(0)}(n+1)$ into $x^{(0)}$; then, the model established by $x^{(0)}=\left(x^{(0)}(1), x^{(0)}(2), \ldots, x^{(0)}(n), x^{(0)}(n+1)\right)$ is called new information GM $(1,1)$; if the latest information $x^{(0)}(n+1)$ is inserted and the oldest information $x^{(0)}$ is removed, the prediction model established with $x^{(0)}=$ $\left(x^{(0)}(2), \ldots, x^{(0)}(n), x^{(0)}(n+1)\right)$ is called metabolic GM $(1,1)$ model [30].

In order to ensure the robustness of the results, this article sets the data of 2017, 2018, and 2019 as the test group and takes the rest of the data as the training group. The data of the training group were trained three GM $(1,1)$ models, and the trained models are used to predict the data of the test group. Finally, the residual sum of squares (RSS) of the three models is calculated, and the model with the smallest RSS is selected as the prediction model of the index value.

5.2. Estimation Method of Policy Implementation Effect. In order to verify whether there is an economic causal relationship between the proposed policy and the improvement of higher education development level in Turkey, this article uses the synthetic control method (SCM) to estimate the size and significance of policy effect. The following is a brief introduction to the SCM [31, 32].

If the $J+1$ countries were divided into two groups, Turkey is set as the first country and the treatment group and the other $J$ countries were set as the control group. Suppose that the observation period is $[1, T]$ and $T_{0} \in(1, T)$ is the time point of policy occurrence. Define $j=\{1, \ldots, J+1\}, t=\{1, \ldots, T\} . S_{j t}$ is the observable higher education development scores of country $j$ at $t . S_{j t}^{N}$ is the scores of country $j$ when the improvement policy is not implemented, $S_{j t}^{I}$ is the scores of country $j$ when the improvement policy is implemented, and $D$ is the dummy variable of whether the policy is implemented or not. If the country has implemented the policy, then $D=1$, otherwise 0 . Assuming that the model is $S_{j t}=S_{j t}^{N}+D_{j t} \alpha_{i t}$, then there is equation $S_{j t}=S_{j t}^{N}$ for countries that do not implement policies, whereas for countries that implement policies, there is equation $\alpha_{j t}=S_{j t}^{I}-S_{j t}^{N}=S_{j t}-S_{j t}^{N}$ at $t>T_{0} . \alpha_{j t}$ is the policy effect that needs to be estimated, but $S_{j t}^{N}$ cannot be observed at this time. We need to estimate it by establishing the following predictive variable model:

$$
S_{j t}^{N}=\delta_{t}+\theta_{t} Z_{j}+\lambda_{t} \mu_{j}+\varepsilon_{j t} .
$$

In equation (23), $\delta_{t}$ is the common time trend term affecting the development of higher education, vector $Z_{j}$ contains various predictive variables, $\theta_{t}$ is the unknown parameter vector, $\mu_{j}$ is the fixed effect, $\lambda_{t}$ is the unobservable potential common factor, and $\varepsilon_{j t}$ is the error term with the mean value of 0 . In order to fit the unobservable $S_{j t}^{N}$, we need to find a weight vector $W(J \times 1)$. For $j=2, \ldots, J+1$, if conditions $w_{j} \geq 0$ and $\sum_{j=2}^{J+1} w_{j}=1$ are satisfied, then there is the following formula:

$$
\sum_{j=2}^{J+1} w_{j} S_{j t}=\delta_{t}+\theta_{t} \sum_{j=2}^{J+1} w_{j} Z_{j}+\lambda_{t} \sum_{j=2}^{J+1} w_{j} \mu_{j}+\sum_{j=2}^{J+1} w_{j} \varepsilon_{j t} .
$$

Suppose that there is a vector $W^{*}=\left(w_{2}^{*}, w_{3}^{*}, \ldots, w_{J+1}^{*}\right)$ satisfying $\sum_{j=2}^{J+1} w_{j}^{*} Z_{j}=Z_{1}$ and the following equations are also satisfied: 

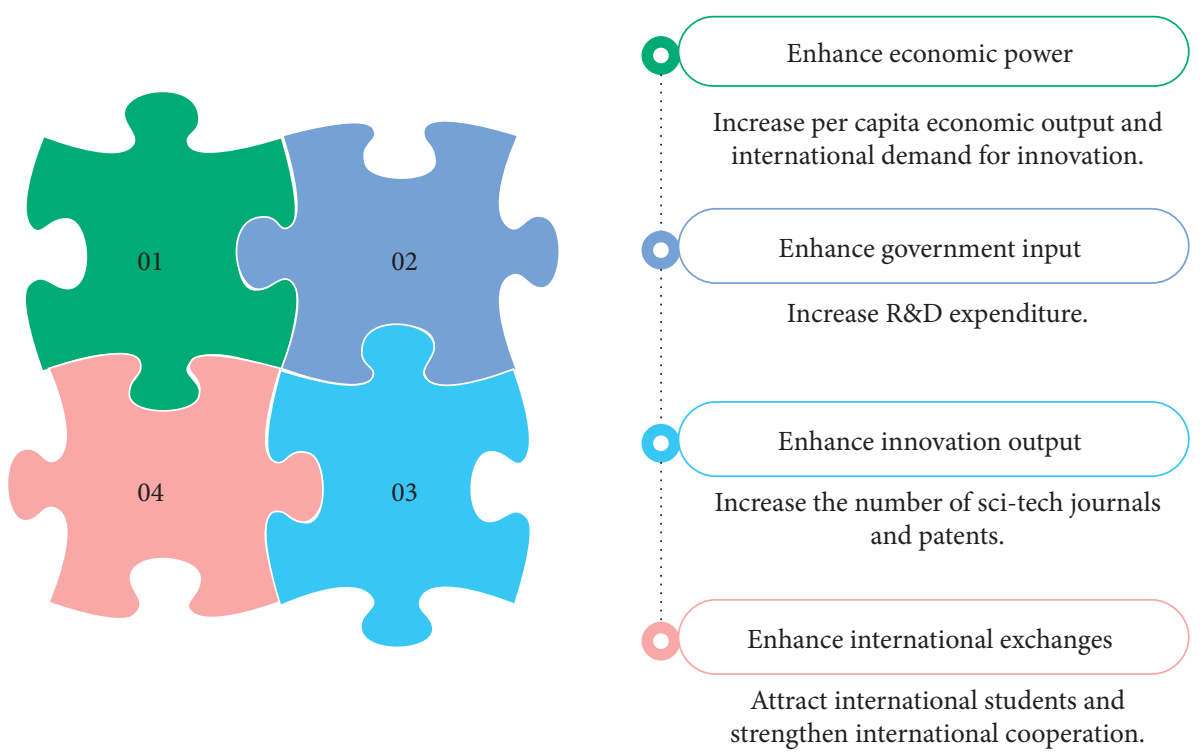

Figure 5: The circular promotion mechanism of policy implementation.

$$
\sum_{j=2}^{J+1} w_{j}^{*} S_{j 1}=S_{11}, \sum_{j=2}^{J+1} w_{j}^{*} S_{j 2}=S_{12}, \ldots, \sum_{j=2}^{J+1} w_{j}^{*} S_{j T_{0}}=S_{1 T_{0}} .
$$

Therefore, after the implementation of our higher education development improvement policy in Turkey, $\sum_{j=2}^{J+1} w_{j}^{*} S_{j t}$ can be used as the unbiased estimator of $S_{1 t}^{N}$ within $T_{0}<t \leq T$. Then, the unbiased estimator $\widehat{\alpha}_{1 t}=S_{1 t}-\sum_{j=2}^{J+1} w_{j}^{*} S_{j t}$ of policy effect $\alpha_{1 t}$ is obtained and recorded as average treatment effect $\left(\mathrm{ATE}_{t}\right)$. For the approximate solution of the weight vector $W^{*}$, the detailed mathematical derivation steps can refer to A. Abadie, A. Diamond, and J. Hainmueller (2010).

The root mean square error (RMSE) between the real series and the synthetic series before the implementation of the policy is usually used to evaluate the fitting effect of SCM, which is recorded as Pre_RMSE. Of course, the smaller the Pre_RMSE, the more applicable the SCM. After the policy is implemented, the RMSE between the real series and the synthetic series is used to evaluate the postpolicy effect, which is recorded as Post_ RMSE.

5.3. Results of Policy Effect Estimation. Continue to forecast 16 index values of 19 countries by the grey prediction model, and the forecast period is 2020-2030. The forecast data of the indicators are combined with the original data, and the forecast values of the six indicators in Turkey's policy planning in 2020-2030 are replaced with the corresponding planning values, which are increasing with equal differences. Then, the TOPSIS method was used to calculate the scores of higher education development level of Turkey and the control group after the implementation of the policy. According to the previous research design, the values of 16 indicators are set as the predictive variables. The expected policy effect of Turkey's higher education improvement plan is obtained by using the SCM, as shown in Figure 6.
It can be seen that there is no significant difference between the synthetic series and the real series of Turkey's higher education development level score before the implementation of the 2020 policy, and the two curves almost coincide, which indicates that SCM has a good fitting effect. After the implementation of the policy, the score of the real series is significantly higher than that of the synthetic series; that is to say, the improvement plan proposed by us can make Turkey get a higher score of higher education development, and the post-average treatment effect of the policy is about 0.016 , which indicates that the higher education development score of Turkey will increase by 0.016 every year in the next 10 years.

In order to describe the policy effect of the treatment group, some tests are needed to prove that the treatment effect of the hypothesis policy is not accidental. There are two main test methods: the placebo test and ranking test. Firstly, we estimated 18 control group countries according to the same synthetic control model setting as Turkey, even though these control group countries may not implement our proposed improvement plan in the future. Then, we observed and compared the average treatment effect series $\left(\mathrm{ATE}_{t}\right)$ of Turkey and control group countries.

If Turkey's $\mathrm{ATE}_{t}$ is greater than that of other countries in the control group, the policy effect proposed by us is not accidental and is statistically significant. This test method is called the placebo test. If we calculate the ratio of the root mean square error (Post/Pre_RMSE) of the control group and Turkey, that is, Post/Pre_RMSE = Post_RMSE/Pre_RMSE, after ranking all the countries in Post/Pre_RMSE, we find that Turkey is in the top, which can again show that the policy implementation is effective. This test method is called the ranking test.

Of course, not all countries in the control group can be included in the framework of placebo test and ranking test. We set 5 times Pre_RMSE of Turkey as the threshold of screening control group. If a country of the control group is 


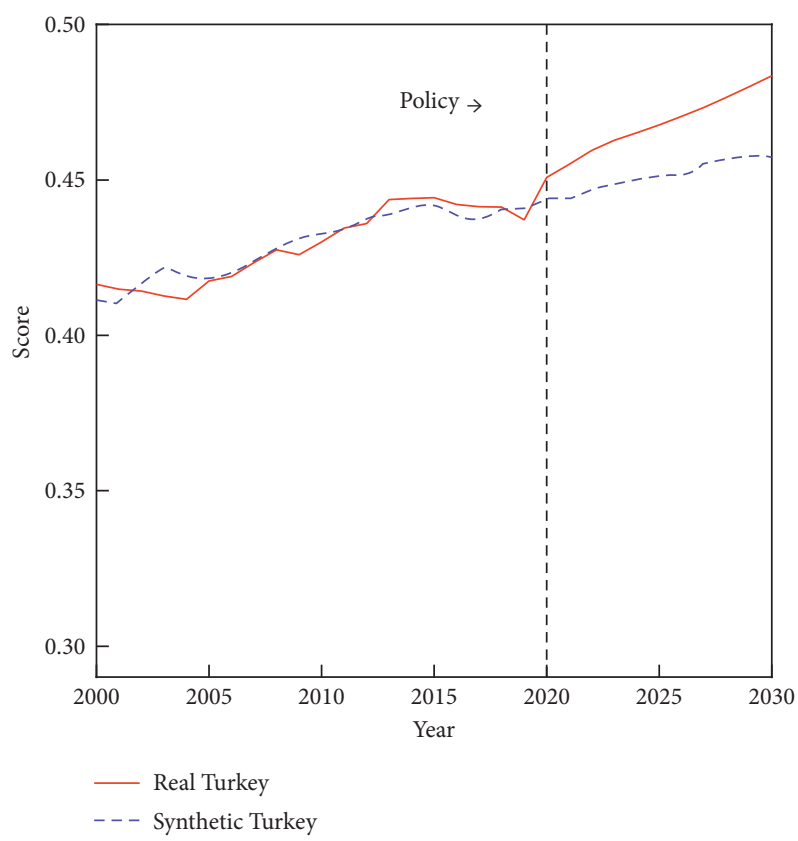

FIgURE 6: Estimation of policy effect of Turkey's higher education development plan.

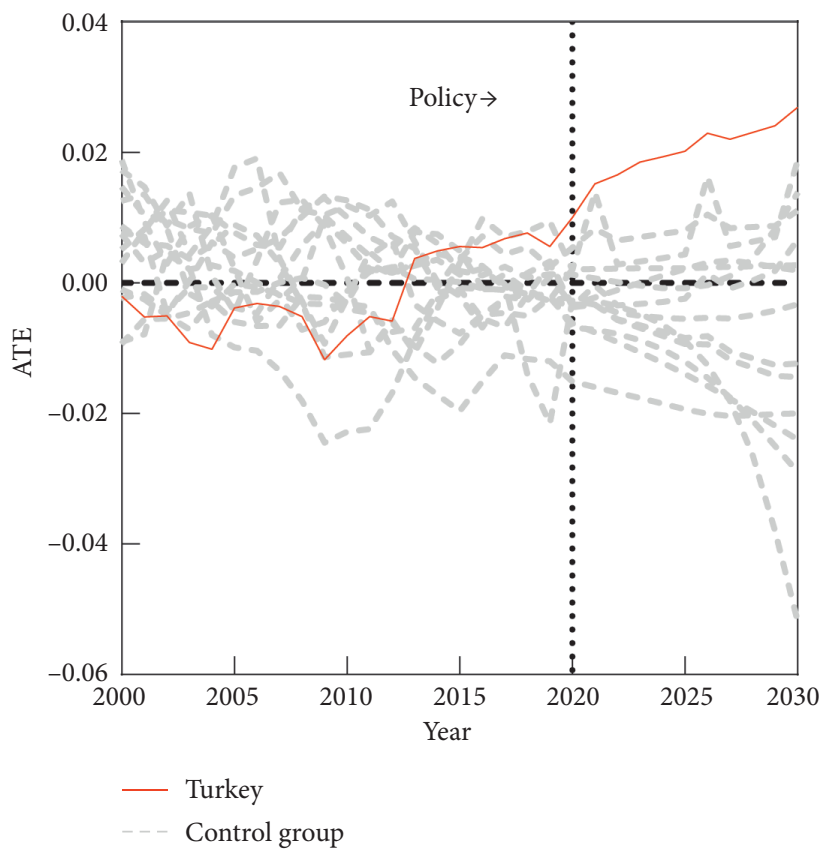

Figure 7: Placebo test of policy effect of Turkey's higher education development plan.

greater than the threshold, it will be excluded because the prefitting effect of these countries is not ideal, which will bring serious interference to the ranking of $\mathrm{ATE}_{t}$.

Figures 7 and 8 show the results of placebo and ranking tests, which found that after policy implementation, Turkey's
$\mathrm{ATE}_{t}$ and Post/Pre_RMSE are higher than other countries, which shows that the results of SCM are robust. Moreover, the improvement policy can significantly improve the overall level of higher education development in Turkey in the next 10 years. 


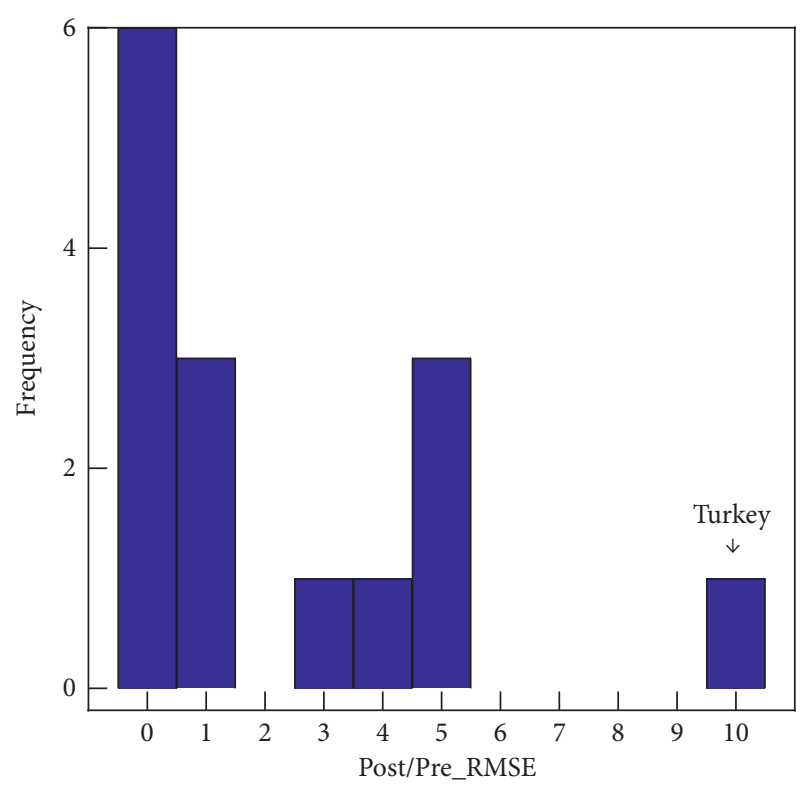

Figure 8: Ranking test of policy effect of Turkey's higher education development plan.

\section{Conclusion}

According to the relevant theories, this article establishes a comprehensive evaluation index system of higher education development level and uses the combination weighting method and TOPSIS method to calculate the score of higher education development level of each country. Through comparison, it is found that developed countries tend to have a higher level of development, whereas developing countries have a relatively low level of development.

We further set Turkey as the target country to formulate improvement policies and use the obstacle factor diagnostic model to find the core obstacles of higher education development. This article also puts forward the corresponding policy improvement plan. Using the SCM to evaluate the effectiveness of the policies we provided, the results show that the policies we proposed enable Turkey to obtain higher scores of higher education development level. In the next 10 years, if we can fully implement our proposed improvement policy, Turkey's higher education development score will increase by about 0.016 per year. The placebo test and ranking test show that the implementation of higher education improvement policy in Turkey is significantly not zero, indicating that the empirical conclusion of this article is robust.

In short, we believe that it is very difficult to realize the reform of higher education development, which requires the joint efforts and active cooperation of the international community, the government, and higher education institutions $[33,34]$. All countries should put economic development in the first place, provide a continuous driving force for the development of higher education, strengthen national innovation ability, and seek opportunities for the development of all humankind [35].

\section{Data Availability}

The data used to support the findings of this study are included within the article.

\section{Disclosure}

Huan-Ming Zhang and Rui-Qi Ma are the co-first authors.

\section{Conflicts of Interest}

The authors declare that there are no conflicts of interest regarding the publication of this article.

\section{Acknowledgments}

This work was supported by the Key Project of Humanities and Social Science in Universities of Anhui Province (SK2020ZD004) and the Graduate Research and Innovation Fund of Anhui University of Finance and Economics (ACYC2020253).

\section{References}

[1] R. M. Solow, "A contribution to the theory of economic growth," The Quarterly Journal of Economics, vol. 70, no. 1, pp. 65-94, 1956.

[2] R. E. Lucas, "On the mechanics of economic development," Journal of Monetary Economics, vol. 22, no. 1, pp. 3-42, 1988.

[3] R. M. Romer, "Endogenous technological change," Journal of Political Economy, vol. 98, no. 5, pp. 1002-1034, 1990.

[4] P. Aghion, "Higher education and innovation," Perspektiven Der Wirtschaftspolitik, vol. 9, no. 3, pp. 28-45, 2008.

[5] F. Tödtling, P. Lehner, and A. Kaufmann, "Do different types of innovation rely on specific kinds of knowledge interactions?" Technovation, vol. 29, no. 1, pp. 59-71, 2009.

[6] H. Etzkowitz and L. Leydesdorff, "The dynamics of innovation: from national systems and "mode 2" to a triple helix of university-industry-government relations," Research Policy, vol. 29, no. 2, pp. 109-123, 2000.

[7] E. A. Hanushek and L. Woessmann, "The economics of international differences in educational achievement," National Bureau of Economic Research, vol. 3, pp. 89-200, 2010.

[8] E. A. Hanushek and L. Woessmann, "Do better schools lead to more growth? Cognitive skills, economic outcomes, and causation," Journal of Economic Growth, vol. 17, no. 4, pp. 267-321, 2012.

[9] E. Baldacci, B. Clements, S. Gupta, and Q. Cui, "Social spending, human capital, and growth in developing countries," World Development, vol. 36, no. 8, pp. 1317-1341, 2008.

[10] T. Schultz, "Investment in human capital," American Economic Review, vol. 51, pp. 1-17, 1961.

[11] X. Y. Ye and Y. Q. Ding, "Expanding Chinese higher education: quality and social stratification," Chinese Journal of Sociology, vol. 35, no. 3, pp. 193-220, 2015.

[12] S. Marginson, "The worldwide trend to high participation higher education: dynamics of social stratification in inclusive systems," Higher Education, vol. 72, no. 4, pp. 413-434, 2016.

[13] N. Powdthavee, W. N. Lekfuangfu, and M. Wooden, "What's the good of education on our overall quality of life? A simultaneous equation model of education and life satisfaction for Australia," Journal of Behavioral and Experimental Economics, vol. 54, pp. 10-21, 2015. 
[14] M. E. P. Seligman, R. M. Ernst, J. Gillham, K. Reivich, and M. Linkins, "Positive education: positive psychology and classroom interventions," Oxford Review of Education, vol. 35, no. 3, pp. 293-311, 2009.

[15] W.-C. Chen, "How education enhances happiness: comparison of mediating factors in four east asian countries," Social Indicators Research, vol. 106, no. 1, pp. 117-131, 2012.

[16] J. Cuñado and F. P. de Gracia, "Does education affect happiness? evidence for Spain," Social Indicators Research, vol. 108, no. 1, pp. 185-196, 2012.

[17] W. J. Ying and Q. Y. Li, "The design and application of performance evaluation index system in colleges," Journal of National Academy of Education Administration, vol. 2010, no. 2, pp. 45-50, 2010.

[18] J. Zeira, "Innovations, patent races and endogenous growth," Journal of Economic Growth, vol. 16, no. 2, pp. 135-156, 2011.

[19] N. X. Zhang and S. Wang, "An evaluation and regional comparison of the holistic development of Chinese higher education," Educational Research, vol. 35, no. 5, pp. 28-36, 2014.

[20] X. Chen and B. Liu, "Dynamic comprehensive evaluation of investment efficiency of China's higher education," Statistics \& Decision, vol. 32, no. 20, pp. 44-48, 2020.

[21] Y. Liu and N. Li, "The establishment of the assessment indicator set of higher education internationalization competence," Journal of Higher Education Management, vol. 13, no. 5, pp. 52-60, 2019.

[22] Y. Liu and N. Li, "Research and judgement on the evaluation index system of higher education internationalization-based on the comparison of 9 evaluation index systems," Heilongjiang Higher Education Research, vol. 38, no. 8, pp. 77-83, 2020.

[23] J. W. Gillard, "An initial analysis and reflection of the metrics used in the teaching excellence framework in the UK," Perspectives: Policy and Practice in Higher Education, vol. 22, no. 2, pp. 49-57, 2017.

[24] G. D. Kuh, "Assessing what really matters to student learninginside the national survey of student engagement," Change: The Magazine of Higher Learning, vol. 33, no. 3, pp. 10-17, 2001.

[25] J. Ma, Z.-P. Fan, and L.-H. Huang, "A subjective and objective integrated approach to determine attribute weights," European Journal of Operational Research, vol. 112, no. 2, pp. 397-404, 1999.

[26] X. P. Lei, G. H. Qiu, and Y. Liu, "Evaluation of regional land use performance based on entropy TOPSIS model and diagnosis of its obstacle factors," Transactions of the Chinese Society of Agricultural Engineering, vol. 32, no. 13, pp. 243253, 2016.

[27] F. Xu, Y.-A. Du, H. Chen, and J.-M. Zhu, "Prediction of fish migration caused by ocean warming based on SARIMA model," Complexity, vol. 2021, Article ID 5553935, 9 pages, 2021.

[28] R. Xie, R. Liu, X.-B. Liu, and J.-M. Zhu, "Evaluation of SMEs' credit decision based on support vector machine-logistics regression," Journal of Mathematics, vol. 2021, Article ID 5541436, 10 pages, 2021.

[29] J. L. Deng, "Introduction to grey system theory," Journal of Grey System, vol. 1, no. 1, pp. 1-24, 1989.

[30] S. Q. Hua, S. Hao, C. Zeng, and X. J. Hao, “Application of gray metabolic GM $(1,1)$ model in prediction of annual total yields of Chinese aquatic products," Asian Agricultural Research, vol. 5, no. 3, pp. 21-25, 2013.
[31] A. Abadie and J. Gardeazabal, "The economic costs of conflict: a case study of the Basque country," American Economic Review, vol. 93, no. 1, pp. 113-132, 2003.

[32] A. Abadie, A. Diamond, and J. Hainmueller, "Synthetic control methods for comparative case studies: estimating the effect of California's tobacco control program," Journal of the American Statistical Association, vol. 105, no. 490, pp. 493$505,2010$.

[33] J. B. Liu, J. Zhao, and J. Min, "On the hosoya index of graphs formed by a fractal graph," Fractals-Complex Geometry Patterns and Scaling in Nature and Society, vol. 27, no. 8, pp. 19-35, 2019.

[34] X.-B. Liu, Y.-J. Zhang, W.-K. Cui, L.-T. Wang, and J.-M. Zhu, "Development assessment of higher education system based on TOPSIS-entropy, hopfield neural network, and cobweb model," Complexity, vol. 2021, Article ID 5520030, 11 pages, 2021.

[35] J.-M. Zhu, Y. Chen, and S. Zhang, "Analysis of the impact of climate change on national vulnerability based on fuzzy comprehensive evaluation," Discrete Dynamics in Nature and Society, vol. 2020, Article ID 3527540, 10 pages, 2020. 